\title{
A Study on the Standard and Material Safety of Air Conditioning Worker's Equipment in South Korea by Structural Analysis
}

\author{
${ }^{1}$ Sanghyun Kim, ${ }^{2}$ Hyunsub Lee, ${ }^{3}$ Dongyoon Shim, ${ }^{1}$ Keunoh Lee and ${ }^{4}$ Chankyu Kang \\ ${ }^{1}$ Department of Safety Engineering, Seoul National University of Technology, 232 Gongneung-ro, \\ Nowon-gu, 01811 Seoul, Republic of Korea \\ ${ }^{2}$ Korea Occupational Safety and Health Agency, Construction and Safety Division, 400 Jonggaro, \\ Jung-gu, 44429 Ulsan, Republic of Korea \\ ${ }^{3}$ Korea Occupational Safety and Health Agency, Service Safety Division, 140 Chudongro, \\ Uijeongbu, 11780 Gyeonggi, Republic of Korea \\ ${ }^{4}$ Ministry of Employment and Labor, Gyungju Regional Office, \\ Center for Major Industrial Accident Prevention, \\ 10 Jungheung 2-ro, Yeosu-si, 59631 Jeonnam, Republic of Korea
}

\begin{abstract}
It is a reality that subcontracting for the completion of work is becoming globalized and the risk of such work is being outsourced. In this study, we tried to secure the safety of the air conditioner worker through structural examination of the protection area (equipment with a safety bar) which is a representative example of domestic outsourcing. However, there is no proper protective standard that can work safely during the installation and repair process of air conditioners in Korea and there is no obligatory safety check before the product is released. Equipment with safety bars was judged according to the performance standards presented in preparation for falls and safety verification was determined by simple structural analysis rather than complicated numerical simulation. In order to more easily obtain products that satisfy the safety performance criteria, a proper cross-section was calculated and tested through experimentation with change of load and deflection rather than through repetitive fabrication.
\end{abstract}

$\underline{\text { Key words: } \text { Air conditioner, risk, safety bar, load, deflection, calculated }}$

\section{INTRODUCTION}

A safe life is an essential element in human nature, and it is clear that the desire for safety by avoiding danger and suffering is the next step in physiological desire safety is the foundation for people to lead a happy life (Maslow, 1943). However, the labor environment has rapidly changed due to industrialization and as a result of the development of new technologies, new and complex risk factors have emerged which have become an imperative threat to worker's safety in recent years (Thimbleby, 2013). In particular, outsourcing for the efficient management of industries has become a trend of global labor and the frequency with which subcontract workers are exposed to risk is increasing (Diaz-Mora, 2008; Mankiw and Swagel, 2006). In fact, the number of fatalities of subcontract workers whose safety management capabilities are weak is rising because the outsourcing of risk has increased in South Korea from $39.9 \%$ in 2014 to $42.3 \%$ in 2015 and $42.5 \%$ in
2016 (http://www.moel.go.kr/news/enews/report, 2017). Protection legislations for subcontracted workers who work in the form of these contracts have different systems based on countries. For example, occupational health and safety responsibility are defined as general obligations of employers in the UK (http://www.hse. gov. $\mathrm{uk} /$ pubns/hsal3.pdf, 2008). As a result, there is no need for the employer to maintain specific rules for occupational safety and health actions for in-house subcontracted workers. However, in principle, the employer's safety and health obligations are limited to the workers who have contracts with him/her. Other provisional legislations are needed for the public protection of the safety and health of subcontracted workers in the case of Germany, Japan and Korea (Drahokoupil, 2015; Reich and Frumkin, 1988).

In South Korea, accidental falling deaths occurring during the installation of outdoor air conditioners has been identified as a representative example of 'risk outsourcing' and emerged as a social issue in 2016

Corresponding Author: Chankyu Kang, Ministry of Employment and Labor, Gyungju Regional Office, Center for Major Industrial Accident Prevention, 10 Jungheung 2-ro, Yeosu-si, 59631 Jeonnam, Republic of Korea 
(Kim et al., 2017). In particular, the demand for air conditioners is increasing due to the recent high temperature phenomenon and IT technology development in the global summer but the safety of outdoor air conditioner installation and repair workers is being ignored. There is an especially high risk of falling accidents due to high-altitude operation when installing outdoor units. It is because the installation of the air conditioner outdoor without safety attaching equipment is risky if the worker uses the lifeline and can't bear the weight of the worker during the installation work. Since, equipment for preventing falls is not required for safety certification, there exist limited studies to confirm the material properties of safety bars (DiGuiseppi et al., 2010).

Although, the industrial applications are different, various studies have been carried out on the characterization of material properties for safety equipment. Most of the research is currently being done in the field of automobiles but as the trend of high-rise buildings increases around the world, more research will be done in this field. Shi and $\mathrm{Xu}$ (2018) evaluated the stability of seat belts by selecting the front row seat of the vehicle as the main study subject, reducing the number of physical tests and shortening the design cycle (10). Shi et al. (2017) performed a strength test of the safety-belt ISOFIX of the automobile seat according to the standard of GB14167-2013 and analyzed the stress and strain nephogram using HyperWorks Software. The Health and Safety Executive (HSE) investigated the combined effects of different types of damage affecting the breaking strength of the webbing used to manufacture safety harnesses and lanyards (Hill, 2007). It concluded that the combination of weathering, abrasion, ingress of dirt and edge damage provided the most severe case. Dolez and Vu-Khan (2009) introduced the technology of nanomaterials and smart textiles to reduce both the mechanical risks and chemical aggressors of protective equipment. Gadenin (2013) analyzed the marginal states of the structural components of the material by analysing their mechanical properties. Several parameters were used to determine the safety operation requirements of the equipment based on the risk concept.

The purpose of this study is to obtain a product that satisfies the performance standard of protective equipment to prevent accidental falls of air conditioner workers. Also, simple structure analysis was used to try to secure stability without using complex numerical simulations. For this purpose, structural analysis was carried out based on the results of the strength test of the material in order to obtain a suitable cross section of the equipment with the safety bar along with a simple calculation. Based on the safety certification standard of the Korean protector, a three-point bending test was conducted to examine the deflection by the load on the equipment attached to the safety bar based on the safety certification standard of the Korean protector. As a result, a suitable cross-section of the equipment with the safety bar was presented.

\section{MATERIALS AND METHODS}

Sample preparation: The equipment with the safety bar was manufactured in a form in which the inner pipe and the outer pipe were separated in consideration of the convenience of carrying. When used they are manufactured in a combined form, so that, the inner pipe and the outer pipe are easily combined. Figure 1a shows the shape of the inner and outer pipes of the equipment. The safety bar is a structure combining the inner and outer pipes and is fixed in place by the escape prevention screw (one place) attached to the center.

Two types of prototype samples were fabricated for the equipment used in the experiment. Table 1 shows the specification of the prototype samples. The equipment in the experiment with the safety bar was made of carbon steel SPSR 400 (Hyundai Steel, Danjin, South Korea) a 100t tensile tester of Quro Co. (Yaungsi, South Korea), shown in Fig. 1b was used to analyze bending strength. Each experiment was repeated at least three times to obtain reliable data. Two safety bars as shown in Table 1, were prepared to ensure that the air-conditioner workers could secure their safety during outdoor work while at the same time procuring light-weight safety bars. Samples 1 and 2 prepared in this study were composed of inner and outer pipes, so that, they could be easily joined together with only a small gap. Sample 2 was prepared by tack welding 20,20 and $25 \times 25 \mathrm{~mm}$ tubes of each of the existing products in order to increase the sectional rigidity at the level of $63 \%(\mathrm{~V} 2 / \mathrm{V} 1 \times 100)$ of sample 1 's weight.

Bending stress analysis: For the bending stress measurement, a steel iron door frame, mainly used in the construction of apartment buildings was used in accordance with the Korean Industrial Standard (KS F 3109:2014). The equipment with the safety bar was installed in accordance with the gap between the door frames $(990 \mathrm{~mm})$ and both ends were fixed with clamps as shown in Fig. 2a. The safety of the bar was determined after the concentrated load of $15 \mathrm{kN}$ was applied to the center section, the safety of the safety bar was determined as shown in Fig. 2b. Since, there is no separate criterion for only the safety bar components, the performance standard for safety bars proposed in the safety 

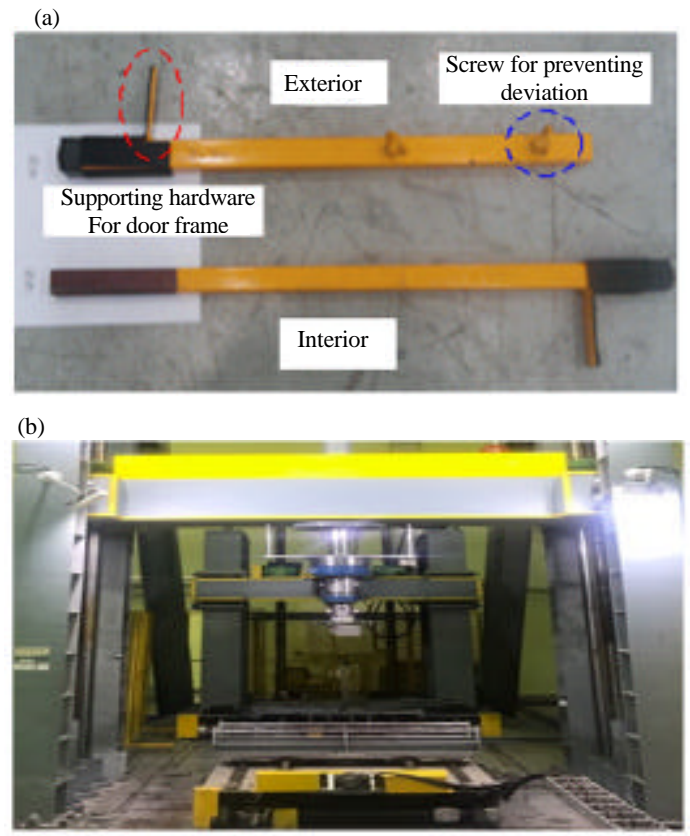

Fig. 1: a)Inner and outer pipes of safety bar and b) Tensile testing machine

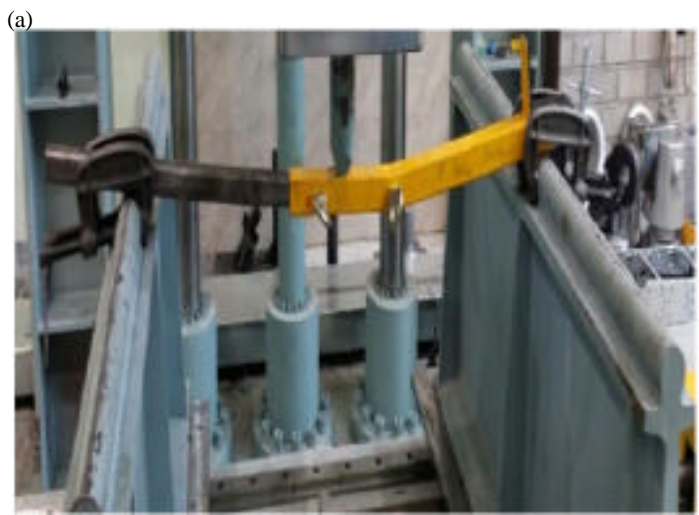

(b)

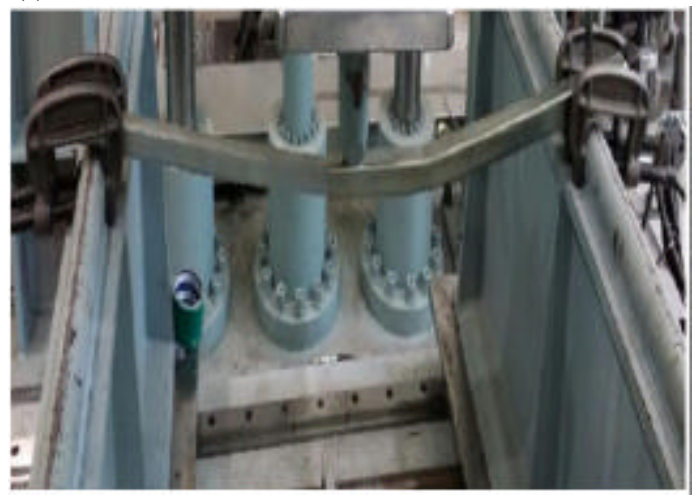

Fig. 2: a) Experimental analysis of the safety bar and b) Bending phenomenn of equipment for attaching safety bars
Table 1: Specifications of prototype attachment equipment

\begin{tabular}{|c|c|c|c|}
\hline Types & Sample 1 & & Sample 2 \\
\hline \multicolumn{4}{|l|}{ Length } \\
\hline Inner & $800 \mathrm{~mm}$ & & $740 \mathrm{~mm}$ \\
\hline Outer & $700 \mathrm{~mm}$ & & $650 \mathrm{~mm}$ \\
\hline \multicolumn{4}{|l|}{ Carbon steel SS } \\
\hline \multirow[t]{2}{*}{ Inner } & $32 \times 32 \mathrm{~mm}(4.2 \mathrm{t})$ & I.D & $20 \times 20 \mathrm{~mm}(2.0 \mathrm{t})$ \\
\hline & & O.D & $25 \times 25 \mathrm{~mm}(2.0 \mathrm{t})$ \\
\hline Outer & $40 \times 40 \mathrm{~mm}(2.0 \mathrm{t})$ & & $30 \times 30 \mathrm{~mm}(1.75 \mathrm{t})$ \\
\hline Overlap Length & $220 \mathrm{~mm}$ & & $200 \mathrm{~mm}$ \\
\hline Volume & $586432 \mathrm{~mm}^{3}$ & & $371257 \mathrm{~mm}^{3}$ \\
\hline Fixed status for overlap & Overlap preventio & & \\
\hline
\end{tabular}

certification notice of South Korea was applied. According to the performance standard of the safety bar to be worn when the worker is at risk of falling during work, it was confirmed that there was no breakage or loss of function when holding a $15 \mathrm{kN}(1,530 \mathrm{kgf})$ static load for $1 \mathrm{~min}$.

Structural review: The geometry of the inertia depends on the cross-sectional shape of the material. For a square, it is calculated using (Eq. 1) (Huang and Gibson, 1993):

$$
\mathrm{I}_{\mathrm{x}}=\frac{\mathrm{bh}^{3}}{12}
$$

Where:

$\mathrm{b}=$ The length of the horizontal and

$\mathrm{h}=$ The height

Table 2 shows the cross-sectional specifications of the equipment for attaching the restraints. The test performance of the attachment safety bar was determined by the difference of the geometry of the inertia of the external and internal pipes. A structural review was conducted to determine the proper cross-section that meets the performance criterion. Several conditions were assumed for the review of the structure) equipment with the safety bar has a constant section in the longitudinal direction) it does not take into account the internal and external clearances) the fastenings at both ends are fully fixed and) there is no slip on the contact areas for preventing the inner pipe and the outer pipe from being separated from each other. Under these assumptions, the maximum bending occurs at the center position and the moment of bending at the center is given by Eq. 2 (Gere and Goodno, 2012):

$$
M=\frac{P L}{8}
$$

Where:

$\mathrm{M}=$ The central bending moment

$\mathrm{P}=$ The external force

$\mathrm{L}=$ The length of the beam 

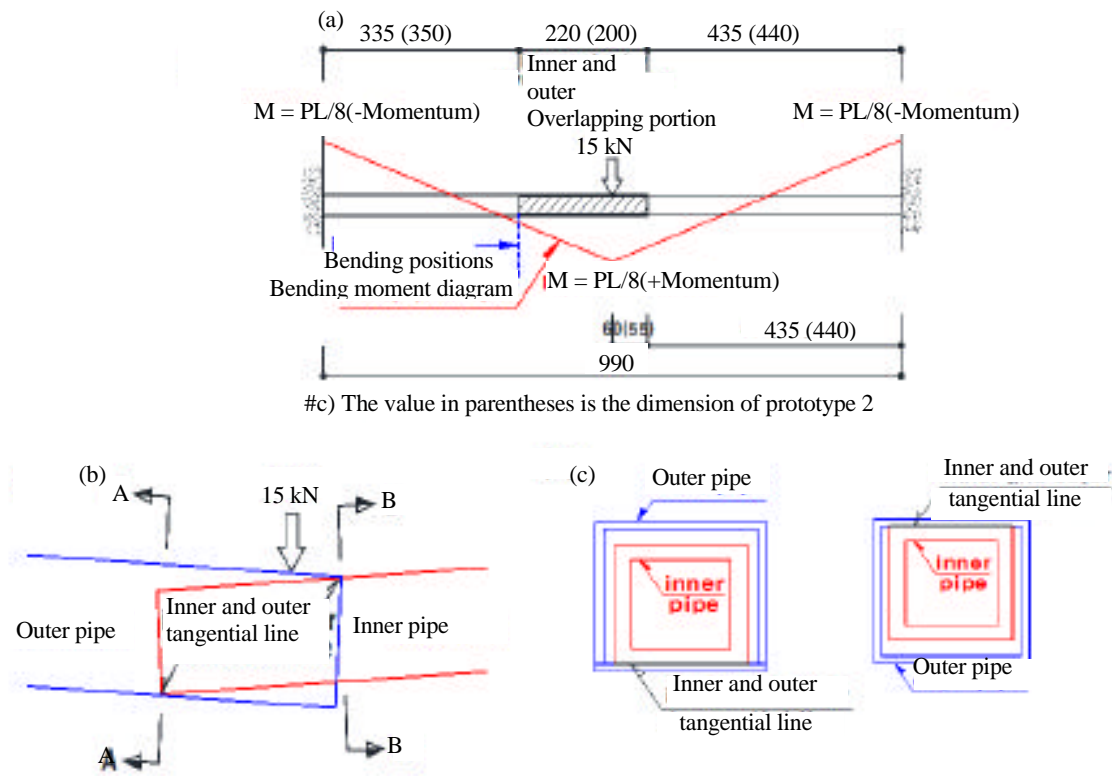

Fig. 3: a) Bending moment diagram of safety bar; b) Shape of internal and external bending and c) Vulnerable areas of inner pipe

\section{RESULTS AND DISCUSSION}

The bending strength analysis with the prepared prototype sample failed to meet the safety standards due to breakage or malfunction when maintaining a static load of $15 \mathrm{kN}(1,530 \mathrm{kgf})$ for $1 \mathrm{~min}$. It was able to withstand $10.91 \mathrm{kN}$ for prototype 1 and $5.73 \mathrm{kN}$ for prototype 2 using Eq. 1. The maximum bending moment of the installation of the safety bar shown in Fig. 3a was expected to occur at both the center position and at the ends that were clamped. However, it is expected that a greater force will be generated at the center because it can be fixed with a clamp to be rotated at the ends. The bending moment was the largest at the center but the stiffness increased rapidly due to the overlap of the inner pipe and the outer pipe. Experimental results also showed that bending occurred at the inner pipe end point where the inner and outer pipes overlapped. This result shows that if the bending occurs due to the gradual increase of the load as shown in Fig. 3b, the inner pipe end point presses the outer surface locally, so that, the stress is concentrated and bending occurs. Where the inner and outer pipes overlap, the outer pipe end point presses the upper surface of the inner pipe and it is presumed that the bending does not occur due to the resistance of the inner pipe. The upper and lower sections affected by the loading given in the inner pipe are shown in Fig. 3c. A structural review of the two prototype samples was examined by using (Eq. 1) under the previously assumed conditions and the structural safety of the bending area was analyzed to identify the moment at which such bending was formed. In the case of prototype 1 it was calculated as follows:

$$
\begin{gathered}
M \frac{P L}{8}=\frac{10910 \mathrm{~N} \times 990 \mathrm{~mm}}{8}=1350 \mathrm{kN} \\
1350 \mathrm{kN} 495 \mathrm{~mm}=\mathrm{M}^{\prime}: 335 \mathrm{~mm}
\end{gathered}
$$

Using the proportional (Eq. 4), the moment of bending (335 mm) can be calculated using the central moment obtained from (Eq. 2). As a result, the bending moment of prototype 1 was $914 \mathrm{kN} . \mathrm{mm}$ and the bending stress was 249.1 MPa which was obtained with Eq. 5:

$$
\sigma=\frac{M y}{I}=\frac{914 \mathrm{kN} \times 20 \mathrm{~mm}}{73365 \mathrm{~mm}^{4}}=249.1 \mathrm{MPa}
$$

In the same way, the moment of the bending position (350 mm) was $709 \mathrm{kN}$ and the bending stress was 284.8 MPa. It is known that the material of SPSR 400 has a nominal yield strength of $245 \mathrm{MPa}$ (Nawy, 2009) and calculated values from two prototype samples were less than $245 \mathrm{MPa}$. Therefore, both prototype 1 and 2 were considered to be insufficient in structural safety beyond the yield strength of the material at the bending positions.

Based on the results of the bending analysis and the structural examination, the appropriate cross-section satisfying the bending strength at the performance 
J. Eng. Applied Sci., 14 (11): 3771-3776, 2019

Table 2: Cross-sectional specifications of the equipment with the safety bar

\begin{tabular}{|c|c|c|c|c|c|c|}
\hline Type & Horizontal length (b) & Height (h) & Thickness & Cross-sectional area & $\mathrm{Y}(\mathrm{h} / 2)$ & Inertia (I) \\
\hline \multicolumn{7}{|l|}{ Prototype 1} \\
\hline Inner & 32 & 32 & 4.20 & 467 & 16.0 & 61531 \\
\hline Outer & 40 & 40 & 2.00 & 304 & 20.0 & 73365 \\
\hline \multicolumn{7}{|l|}{ Prototype 2} \\
\hline Inner/inside & 20 & 20 & 2.00 & 328 & 12.5 & 24217 \\
\hline Outside & 25 & 25 & 2.00 & & & \\
\hline Outer & 30 & 30 & 1.75 & 198 & 15.0 & 26404 \\
\hline
\end{tabular}

Table 3: Specifications of safety bar with modified cross-sectional dimensions

\begin{tabular}{lcccccc}
\hline Classification & Horizontal length (b) & Height (h) & Thickness & Cross-sectional area & Y (h/2) & Inertia (I) \\
\hline Cross-sectional review & & & & & & \\
Inner & 32 & 32 & 4.20 & 467 & 16.0 & 61531 \\
Outer & 40 & 40 & 3.00 & 444 & 20.0 & 101972 \\
\hline
\end{tabular}

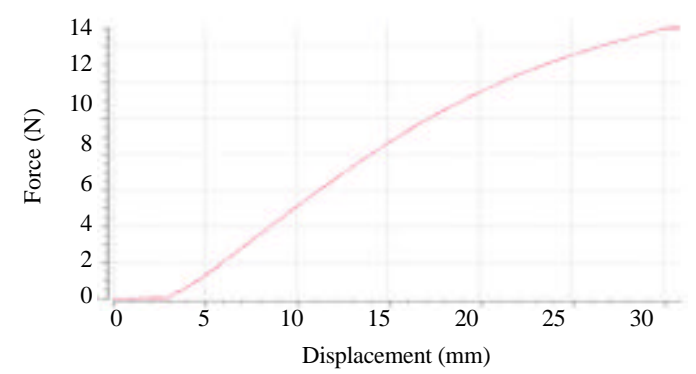

Fig. 4: Bending strength experiment of the safety bar

criterion $(15 \mathrm{kN})$ of the equipment with the safety bar was calculated by a simple method. Considering that the bending position is the inner pipe end point where the inner pipe and the outer pipe overlap each other, increasing the thickness of the outer pipe causes cross-sectional stiffness. In addition, decreasing the clearance of the inner pipe and outer pipe will increase the bending strength. On the basis of this assumption, a structural examination of the prototype sample 1 was performed by changing the cross-section to reach bending stress close to $250 \mathrm{MPa}$. Therefore, the thickness of the outer pipe was adjusted from 2 and $3 \mathrm{~mm}$. Because the bending stress was somewhat higher than the yield strength in the case of the prototype sample 1, it did not show much difference. Therefore, only the thickness was only changed and additional experiments were performed. Table 3 presents the specifications of the equipment of the safety bar.

Equation 2 and 5 were used to carry out the same method as that of the prototype 1. With the change of thickness, the calculated central bending Moment (M) was $1856 \mathrm{kN} \mathrm{mm}$ and the bending stress was $246.4 \mathrm{MPa}$. As a result of the structural examination, the bending stress of the weakest part was similar to the yield strength $(245 \mathrm{MPa})$ at the performance criterion of $15 \mathrm{kN}$. The evaluation of the appropriateness of the result of the structural review was confirmed through actual experiments. Based on the results of the structural examination to determine the appropriate cross-section, the prototype samples were rebuilt and additional strength tests with tensile tester were carried out. The results are shown in Fig. 4. It indicates that the performance standard of the prototype sample was maintained at $15.06 \mathrm{kN}$ for $1 \mathrm{~min}$ with a tensile load of $15 \mathrm{kN}$ or more. However, several prototypes were fabricated and tested in this study in order to overcome the error in the experimental procedure and the results satisfying the bending strength with the performance bar of $15 \mathrm{kN}$ (error $5 \%$ ) were derived.

\section{CONCLUSION}

Outdoor installation of air-conditioning units by subcontract workers has been considered a social problem in South Korea due to the risk of falling accidents. The safety and effectiveness of equipment with safety bar were examined. This study does not use a precise and complicated structural analysis (nonlinear analysis) method considering the clearance of inner and outer appearance, contact conditions of inner and outer surfaces in the case of bending and support conditions supported by the door frame. Instead of a complicated method, a cross-section of the safety bars was derived from information from a simple calculation method through a stress investigation on a simple beam at both ends. The following conclusions were obtained through the bending strength test and structural analysis. In order to secure the safety of the equipment of the safety bar, the safety standard $(15 \mathrm{kN})$ which is the safety certification notice of the protector was applied to investigate the change of deflection (or bending) according to the load and the appropriate cross-sectional area of the safety bar was presented.

Experimental results showed that the inner pipe end point where the inner pipe and outer pipe overlap was weak, therefore, the bending strength was increased by increasing the thickness of the outer pipe and minimizing the inner pipe and outer pipe clearance. Based on the experimental results of the equipment for prototype 
samples 1 and 2 , it was easy to obtain a suitable cross-section that meets the performance criterion $(15 \mathrm{kN})$ through structural analysis rather than repetitive product constructions and tedious experiments.

\section{ACKNOWLEDGEMENT}

This study is a part of the survey and experiments conducted by the Korea Occupational Safety and Health Agency (KOSHA) for the prevention of accidents caused by air conditioner workers.

\section{REFERENCES}

DiGuiseppi, C., D.E. Jacobs, K.J. Phelan, A. Mickalide and D. Ormandy, 2010. Housing interventions and control of injury-related structural deficiencies: A review of the evidence. J. Public Health Manage. Pract., 16: 34-43.

Diaz-Mora, C., 2008. What factors determine the outsourcing intensity? A dynamic panel data approach for manufacturing industries. Appl. Econ., 40: 2509-2521.

Dolez, P.I. and T. Vu-Khanh, 2009. Recent developments and needs in materials used for personal protective equipment and their testing. Intl. J. Occup. Saf. Ergon., 15: $347-362$.

Drahokoupil, J., 2015. The Outsourcing Challenge: Organizing Workers across Fragmented Production Networks. Etui, Brussels, Belgium, ISBN:978-2-87452-366-3, Pages: 294.

Gadenin, M.M., 2013. Characteristics of mechanical properties of materials in studies of conditions of attainment of marginal states. Inorg. Mater., 49: $1352-1356$.

Gere, J.M. and B.J. Goodno, 2012. Mechanics of Materials. 8th Edn., Cengage Learning, Boston, Massachusetts, USA., Pages: 1099.
Hill, H., 2007. Factors affecting the strength of safety harness and lanyard materials-combinations of effects. Msc Thesis, HSL Mathematical Software Library, $\mathrm{UK}$.

Huang, J.S. and L.J. Gibson, 1993. Materials and cross-sectional shapes for bending stiffness. Mater. Sci. Eng. A., 163: 51-59.

Kim, S., J. Seo, S. Shin, D. Sim and K. Lee, 2017. A study on prevention measure safety accident establishment through cause analysis of air-conditioner workers working condition. Proceedings of the Fall Conference on Korea Society of Safety, November 9-10, 2017, Kyungju, South Korea, pp: 1-5.

Mankiw, N.G. and P. Swagel, 2006. The politics and economics of offshore outsourcing. J. Monetary Econ., 53: $1027-1056$.

Maslow, A.H., 1943. A theory of human motivation. Psychol. Rev., 50: 370-396.

Nawy, E.G., 2009. Reinforced Concrete: A Fundamental Approach. Prentice Hall, New Jersey, USA., ISBN:9780132417037, Pages: 915.

Reich, M.R. and H. Frumkin, 1988. An overview of Japanese occupational health. Am. J. Public Health, 78: 809-816.

Shi, P. and Z. Xu, 2018. Analysis of seat belt anchorage strength for vehicles. IOP Conf. Ser. Mater. Sci. Eng., 301: 1-9.

Shi, P., S. Wang and P. Xiao, 2017. Strength analysis on safety-belt ISOFIX anchorage for vehicles based on hyperworks and Ls-Dyna. Proceedings of the International Conference on Neural Information Processing, November 14-18, 2017, Springer, Cham, ISBN:978-3-319-70138-7, pp: 387-396.

Thimbleby, H., 2013. Technology and the future of healthcare. J. Public Health Res., 2: 160-167. 